\title{
QUANDO O SUBALTERNO DESEJA FALAR: O ESCRAVO E A HISTÓRIA REVISTA EM A GLORIOSA FAMÍLIA, DE PEPETELA
}

Isabelita Maria Crosariol Doutoranda em Estudos da Literatura pela Pontifícia Universidade Católica do Rio de Janeiro

\section{RESUMO}

A partir do questionamento levantado por Gayatri Spivak em "Can the subaltern speak?", o ensaio busca refletir sobre o valor que o discurso do narrador (um escravo mudo e analfabeto) assume no romance A Gloriosa Família: o tempo dos flamengos, de Pepetela. Na obra em questão, o escritor angolano parte de um fragmento da obra História geral das guerras angolanas - escrito pelo historiador português António de Oliveira Cadornega no século XVII, e que aborda tanto os sete anos de disputa entre portugueses e holandeses (de 1642 a 1648) pelo controle do comércio de escravos, como o envolvimento de Baltazar Van Dum nesse processo - para questionar uma versão tida como oficial da história, mas que considerou apenas os grandes feitos portugueses. É, então, a partir das lacunas deixadas pela obra de Cadornega que o escravo-narrador proporá uma versão alternativa para essa história, na qual estarão incluídos não apenas fatos menos gloriosos envolvendo a família de Baltazar e as disputas entre portugueses e holandeses, mas também personagens silenciadas pelo discurso ocidental. Como apoio teórico para as reflexões, foram tomados ensaios e obras da teoria pós-colonial, produzidos por autores como Homi Bhabha, Stuart Hall e Ana Mafalda Leite.

PALAVRAS-CHAVE: subalternidade, silenciamento, história revista.

\section{ABSTRACT}

From the question raised by Gayatri Spivak in "Can the subaltern speak?", this essay reflects on the value that the speech of the narrator (a mute and illiterate slave) assumes in the novel A Gloriosa Família: o tempo dos flamengos, of Pepetela. In this novel, the Angolan writer resorts to a fragment of the História geral das guerras angolanas - a work written by the Portuguese historian Antonio de Oliveira Cadornega in the seventeenth century, which discusses both the seven years of dispute between Portugal and Netherlands (1642 to 1648) for the control of the slave trade, and the involvement of Balthazar Van Dum in this process - to question a version of history taken as official, but that has taken only the big Portuguese achievements into consideration. It is, then, from the gaps left by the work of Cadornega that the narrator-slave proposes an alternative version to that story, which includes not only the least glorious facts involving the family of Baltazar and the disputes between Portugueses and Dutches, but also the characters silenced by the Western discourse. As a theoretical support for the reflections, some essays and works of postcolonial theory were taken, such as those written by Homi Bhabha, Stuart Hall and Ana Mafalda Leite.

KEYWORDS: subalternity, silencing, history reviewed. 
Nada tornava provável que surgissem da sombra, aquelas mais do que qualquer outras, com a sua vida e as suas vicissitudes. Podemos divertir-nos, se assim quisermos, a ver nisso uma vingança: a sorte que permite que aquelas pessoas absolutamente destituídas de glória surjam do meio de tantos mortos, que gesticulem ainda, que continuem a manifestar sua ira, a sua aflição ou a sua invencível mania de divagar, talvez compense a má fortuna que sobre elas atraiu, mau grado a sua modéstia e o seu anonimato, o clarão do poder.

Michel Foucault

Publicado na obra $O$ que é um autor, o ensaio de Foucault intitulado "A vida dos homens infames", de 1977, deixava clara a intenção do filósofo de organizar uma "antologia de existências" (2002, p. 89) a partir da seleção de relatos (contendo algumas linhas ou algumas páginas), nos quais eram narradas vidas obscuras e desafortunadas, cujas existências foram silenciadas pelo poder. Assim, em vez de se deparar com a narração da vida de grandes personalidades, o leitor encontraria nessa coletânea a exposição de personagens reais sem qualquer notoriedade ou grandeza, mas que, em meio a suas infelicidades, paixões, amores e ódios, tiveram suas vidas atravessadas "por uma violência, uma energia, um excesso na malvadez, na vilania, na baixeza, na obstinação ou no infortúnio, tais que lhes proporcionassem, aos olhos daqueles que os rodeavam, e à medida da sua própria mediocridade, uma espécie de medonha ou lamentável grandeza" (FOUCAULT, 2002, p. 97).

Segundo Foucault, ao serem retiradas do silenciamento a que foram submetidas durante séculos, essas breves narrativas seriam capazes de emocionar e, ao mesmo tempo, de incitar à reflexão acerca das razões de seu sufocamento no passado - "como se sufoca um grito, um fogo, um animal" (2002, p. 92). Além disso, sendo trazidos à tona no presente (ainda que com por meio da intervenção de outros sujeitos), esses discursos revelariam um desejo de enfrentamento em relação ao poder que subjugou a vida desses homens infames, e que os tomou como seres incapazes de participar ativamente da História. Afinal,

Aquilo que arranca à noite em que elas poderiam, e talvez devessem sempre, ter ficado, é o encontro com o poder: sem este choque, é indubitável que nenhuma palavra teria ficado para lembrar o seu fugidio trajecto. O poder que vigiou aquelas vidas, que as perseguiu, que, ainda que por um só instante, prestou atenção às suas queixas e ao seu leve burburinho e que as marcou com um golpe das suas garras, foi também o poder que suscitou as poucas palavras que delas nos restam: quer porque se lhe tenham querido dirigir para denunciar, apresentar queixa, solicitar, suplicar, quer porque ele tenha pretendido intervir e que com algumas palavras tenha julgado e decidido. (FOUCAULT, 2002, p. 97-8).

Na concepção de Foucault (2002), as vidas desses homens infames, 
destinadas pela sua falta de grandeza a nunca serem ditas, só puderam ser transformadas em relatos em razão de seu contato com o poder. E são justamente esses relatos que legitimam a existência desses indivíduos que "nada tendo sido na história, não tendo desempenhado nenhum papel apreciável nos acontecimentos ou entre as pessoas importantes, não tendo deixado à sua roda qualquer traço que possa ser referido, não têm e nunca mais terão existência a não ser no abrigo precário destas palavras" (2002, p. 100).

Se Foucault, em seu ensaio, parte da recolha de narrativas sobre personagens reais com o intuito de tirá-las do anonimato, e de mostrar suas vidas desprestigiadas como elemento desconsiderado por uma história oficial, será um propósito semelhante que motivará o escritor angolano Pepetela a eleger um escravo mudo e analfabeto (cujo nome nem mesmo é exposto ao longo da narrativa) como narrador do romance A Gloriosa Família: o tempo dos flamengos, de 1997.

Todavia, ao contrário do que podem sugerir o título e o subtítulo da obra, o romance não tematiza os grandes feitos da família de Baltazar Van Dum - o flamengo casado com uma senhora negra (logo, com filhos todos mestiços, fossem os "da casa" ou os "do quintal") que, sendo católico como os portugueses, estava em uma posição vantajosa para lidar tanto com holandeses como com portugueses e, com isso, enriquecer com o tráfico e a venda de escravos (Goulart, 2007) -, tampouco os sete anos (de 1642 a 1648) de ocupação holandesa em Angola, nos quais os mafulos tiveram uma participação intensa no comércio de escravos. Vai além: tematiza o recontar dessa história por alguém considerado incapaz de fazê-lo e, ao longo deste processo, possibilita ao leitor não apenas conhecer suas condições de vida, mas também compreendê-las à luz do contexto de colonização na África.

Stuart Hall, em ensaio intitulado "Quando foi o pós-colonial? Pensando no limite", afirma que:

[...] o termo "pós-colonial" não se restringe a descrever uma determinada sociedade ou época. Ele relê a “colonização" como parte de um processo global essencialmente transnacional e transcultural - e produz uma reescrita descentrada, diaspórica ou "global" das grandes narrativas imperiais do passado, centradas na nação. (2003, p. 109)

Tal afirmação possibilita-nos inferir que: primeiro, o prefixo "pós" não é um marcador temporal, logo, não serve simplesmente para agrupar os discursos produzidos após a independência das antigas colônias; segundo, o "póscolonial" implica sempre um retorno ao passado colonial, uma vez que, sendo a experiência da colonização um fato que ainda ecoa no presente, não se deve, portanto, ignorá-la; terceiro, o voltar ao passado significa adotar uma postura de releitura e de reescrita da colonização, considerando-se para isso não apenas o que foi dito nos discursos coloniais, mas também aproveitando as lacunas 
deixadas naquilo que não foi dito.

Ana Mafalda Leite, em "Pós-colonialismo: um caminho crítico e teórico", corrobora a afirmação de Hall quando argumenta que "a actividade crítica póscolonial é também uma plataforma de reinterpretação da discursividade colonial, por isso o sentido cronológico do termo revela-se insuficiente" (2003, p. 12). Ainda segundo a pesquisadora, o termo "pós-colonial" engloba

[...] todas as estratégias discursivas e performativas (criativas, críticas e teóricas) que frustram a visão colonial, incluindo, obviamente a época colonial; o termo é passível de englobar além dos discursos das ex-colônias da Europa, o conjunto de práticas discursivas, em que predomina a resistência às ideologias colonialistas, implicando um alargamento do corpus, capaz de incluir outra textualidade que não apenas das literaturas emergentes, como o caso de textos literários da ex-metrópole, reveladores de sentidos críticos sobre o colonialismo. (2003, p. 11)

Evidencia-se, assim, por meio do termo "pós-colonial", a existência de discursos e de performances que, ao questionarem as ideologias colonialistas, propõem algo novo, mas não a partir da negação do passado colonial, como lembra Bhabha, e sim a partir da "negociação de instâncias contraditórias e antagônicas, que abrem lugares e objetos híbridos de luta e destroem as polaridades negativas entre o saber e seus objetos e entre a teoria e a razão prático-política" (2007, p. 51, grifo do autor).

O teórico indo-britânico ainda acrescenta que, em meio a este contexto, o presente não deve ser concebido como tempo de ruptura com o passado, nem inocentemente entendido como mero elo entre passado e futuro. O termo "póscolonial", por apontar insistentemente para o além, requer uma nova concepção do presente: o presente como "um lugar expandido e ex-cêntrico da experiência e aquisição do poder" (2007, p. 23), onde o passado não será ignorado, mas recuperado por uma "energia inquieta e revisionária" (2007, p. 23). Desse modo, enquanto

[...] estar no "além" [...] é habitar um espaço intermédio, como qualquer dicionário lhe dirá, [...] residir "no além" é ainda, como demonstrei, ser parte de um tempo revisionário, um retorno ao presente para redescrever nossa contemporaneidade cultural; reinscrever nossa comunidade humana, histórica; tocar o futuro em seu lado de cá. Nesse sentido, então, o espaço intermédio "além" torna-se um espaço de intervenção no aqui e no agora. [...] O trabalho fronteiriço da cultura exige um encontro com o "novo" que não seja parte do continuum de passado e presente. Ele cria uma idéia do novo como ato insurgente de tradução cultural. Essa arte não apenas retoma o passado como causa social ou precedente estético; ela renova o passado, refigurando-o como um "entre-lugar" contingente, que inova e interrompe a atuação do presente. O "passado-presente" torna-se parte da necessidade, e não da nostalgia, de viver. (2003, p. 27, grifo do autor) 
De fato, já no século XVII, António de Oliveira Cadornega, historiador português que aos 15 anos embarcou como soldado para Angola fugindo do provável destino de ser encarcerado em uma das masmorras da Inquisição, já havia descrito em sua História geral das guerras angolanas (evocada no prólogo do livro de Pepetela) as disputas entre holandeses e portugueses pelo território angolano, assim como a participação de Baltazar Van Dum em meio ao acontecimento. Porém, como o romance de Pepetela possibilita perceber, o discurso de Cadornega não é em nenhuma medida imparcial, já que se detém exclusivamente aos grandes feitos portugueses, e ignora qualquer detalhe menos glorioso ou comprometedor:

- Diga-me, senhor alferes. Falou em registar por escrito o que vai observando. Está a escrever um livro sobre estes acontecimentos?

- Ainda não. Por enquanto, só tenho apontamentos dispersos. Penso contar a história heróica dos portugueses nesta terra, desde a fundação da cidade de Luanda. Por isso pergunto detalhes aos que viveram as coisas e registo o que me contam.

- E vai apresentar o governador Sottomayor da maneira como fala dele aqui entre amigos? Porque li algumas crônicas e até poemas sobre os reis e heróis de Portugal, que só cantam coisas sublimes e grandiosas, como se não existissem as menos gloriosas.

Houve uma pausa na conversa, porque Cadornega não respondeu logo. Mas à pausa na fala não se seguiu o barulho dos maxilares nas coxas de frango. Ficaram todos à espera do futuro cronista. E ele teve de limpar a boca com as costas da mão, ganhando tempo de reflexão.

- Chega a ser uma questão moral. Se escrevo sobre as grandezas de Portugal, como posso contar as coisas mesquinhas? Não, essas ficam no tinteiro, pois não interessam para a história. Será necessário saber interpretar a crônica. Personagem que não aparece revestida de grandes encômios é porque não prestava mesmo para nada e só o pudor do escritor salvaguarda sua memória. Assim se tem feito, assim deve ser. (PEPETELA, 1999, p. 269).

O discurso do narrador de A Gloriosa Família, por sua vez, desvincula-se do projeto de narrar apenas os grandes fatos e feitos e, nesse ponto, ainda que a liberdade do escravo seja cerceada, seu discurso é relativamente livre. Consequentemente, ele pode expor não apenas os diálogos que fazem referência aos fatos descritos na obra de Cadornega, mas também as angústias, os sofrimentos e as lutas individuais de homens infames que, como ele, foram silenciados pela versão ocidental da história: o escravo Thor, as escravas Chicomba e Dolores, entre outros.

Importa também notar que, embora o escravo-narrador reiteradamente afirme que a sua missão era apenas a de servir de relator da vida de seu dono "Afinal um escravo nunca tem uma estória interessante, é uma mercadoria que é vendida quando deixa de servir" (PEPETELA, 1999, p. 234) -, o que se verifica na 
verdade é que, ao falar de Baltazar Van Dum e de sua família, indiretamente o escravo também fala de si. É assim que, ao longo da narrativa, o escravonarrador expõe, por exemplo, que ele próprio foi um presente dado pela rainha Jinga a seu atual dono (Baltazar Van Dum), que era mulato - "filho de uma escrava lunda, é certo, mas também de missionário napolitano, louco pelo mato e pelas negras" (PEPETELA, 1999, p. 24) -, que compreendia vários idiomas, e que, apesar de se perceber como um indivíduo sem direitos, sem liberdade, possuía um grande dom, a imaginação - "Sirvo-me sempre dela para completar relatos que me são sonegados, tapando os vazios" (PEPETELA, 1999, p. 14) -, que, aliado à sua grande capacidade de observação e a uma certa dose de magia, possibilitaram-no transmitir a história da "gloriosa família" e também a daqueles que com ele conviveram no anonimato.

Isto significa que, em oposição ao que frequentemente era sustentado e difundido pelos discursos coloniais, esses indivíduos anônimos tinham sim histórias que podiam ser contadas. Talvez fossem histórias que os colonizadores portugueses e holandeses não considerassem "gloriosas". Mas a de Van Dum por acaso era?

De fato, o que a narrativa de Pepetela mostra é que a família de Van Dum não era tão gloriosa assim: Baltazar era um oportunista, alguém que buscava alianças e aproximações visando exclusivamente a seus interesses; D. Inocência, sua esposa, apesar de ser mais escura do que muitos escravos, tratava-os com frieza, e era favorável ao branqueamento da cor e dos costumes; Matilde, a feiticeira da família, não apenas engravidara antes do casamento de um nãocatólico, como também posteriormente traíra seu marido; Rosário se apaixonou por um escravo, Thor, o que custou a vida do rapaz; Ambrósio, por sua vez, casou-se e teve filhos com Angélica Ricos Olhos, uma prostituta estrábica; Hermenegildo era o rapaz afeminado, de cuja sexualidade todos desconfiavam até o dia em que engravidou a escrava coxa Dolores - todos ficaram felizes com a notícia, exceto D. Inocência, que logo exclamou: "Mais um a atrasar a raça" (PEPETELA, 1999, p. 239); Benvindo sentia o peso de ser ridicularizado por sua voz de falsete; Catarina (a grande paixão do narrador) era oprimida por D. Inocência, que também tratava com distinção os demais filhos que seu marido fizera fora do casamento.

O narrador-escravo da obra também expõe que, de modo geral, os homens da "gloriosa família" frequentemente saiam com escravas (quando elas não eram violentadas, consentiam por não terem outra opção), embora raramente assumissem os filhos nascidos dessas relações. Cenas de separação da criança recém-nascida de sua mãe escrava também não eram incomuns, como comprova o fragmento do romance em que Dolores, após ser falsamente acusada de furtar alguns talheres, vê-se forçada a entregar seu filho para D. Inocência, ou a afirmação da também escrava Cichomba de que se fugisse, certamente teria de deixar seu filho: 
- Tu vais deixar o teu filho ir para lá quando a dona quiser?

- Claro que sim. Até o esqueço, quando fugir daqui. Vou eu e ele fica. Assim o pai não vem atrás de mim para recuperar o filho. Não sou burra.

Afinal Chicomba ainda não tinha perdido a esperança de fugir. As conversas com o pobre Thor eram a sério e ela as guardava na memória. Só esperava uma oportunidade. Nicolau muitas vezes ficava fora, como agora. Mas a ausência de Nicolau não era a oportunidade que esperava. Teria de atravessar territórios hostis e podia ser apanhada de novo. Não sei como conseguiria chegar ao seu país natal sem arriscar passar por sítios infestados de jagas, mas ela aguardava pacientemente a sua vez. Entretanto tinha parido um filho de Nicolau que estava disposta a deixar para trás. Chicomba sempre tinha tido um feitio rebelde e decidido, a mansidão actual era um estratagema para a deixarem tranqüila a arquitetar os seus loucos planos de fuga. Mas seriam tão loucos assim? Estou aqui atento a ver. (PEPETELA, 1999, p. 363).

Desse modo, ao contrário do que a história narrada segundo uma perspectiva ocidental comumente mostra, o tratamento desumano dispensado a escravos e escravas não era por eles aceito passivamente. Seja na expressão do desejo de fuga alimentado por Chicomba, seja no retorno de Dolores à casa grande para recuperar seu filho (após fugir do arimo do Bengo, local para onde foi levada como punição pelo furto que nunca cometera), vislumbra-se o desejo dessas escravas de romper com o ciclo de imposição das vontades do colonizador, a partir da afirmação de suas próprias convicções. Ao mesmo tempo, percebe-se no discurso do narrador a constatação de que as atitudes das duas mulheres não eram tão loucas como poderiam parecer, fato que o leva posteriormente a ajudar (ainda que ele assuma timidamente essa participação) o pequeno Gustavo a voltar para os braços de sua mãe:

Percebi, procurava o filho. O qual realmente estava nesse momento na cozinha, com Catarina. Uma idéia louca atravessou de repente a minha cabeça. Era loucura, eu sabia. Mas não pude evitar. Me aproximei da porta da cozinha, onde estava apenas tia e sobrinho. Quando Catarina foi dentro de casa fazer qualquer coisa, puxei Gustavo pela mão. Não ofereceu resistência, adivinhando que eu nunca quereria o mal dele. Com o coração a bater mais forte que quando corria atrás do meu dono até à Baixa, atravessei o pequeno espaço que nos separava da vedação. Chegados à entrada, levantei Gustavo e o sentei em cima do portão, para que ele e a mãe se vissem. Dolores se aproximou, com lágrimas nos olhos. A criança reconheceu-a e estendeu os bracitos, gritando. Que podia eu fazer? Não entreguei o Gustavo, juro que não, apenas não fiz muita força nas mãos que o seguravam. Dolores pegou nele e puxou. As minhas mãos cederam. De repente, sem ter sido minha vontade, o menino estava do outro lado da vedação, livre. (PEPETELA, 1999, p. 371). 
modo de impedir que aquela criança - filha de pai branco e mãe escrava (como ele era), condenada a viver sem a companhia da mãe (como ele viveu) futuramente estivesse em uma condição subalterna semelhante à em que ele próprio se encontrava. É um modo, portanto, de tentar desviar o curso da história, mostrando que a subalternidade não é uma categoria fixa, ao contrário do que veiculavam os discursos coloniais. Como explica Bhabha:

Um aspecto importante do discurso colonial é sua dependência do conceito de "fixidez" na construção ideológica da alteridade. A fixidez, como signo da diferença cultural /histórica/racial no discurso do colonialismo, é um modo de representação paradoxal: conota rigidez e ordem imutável como também desordem, degeneração e repetição demoníaca. Do mesmo modo, o estereótipo, que é a sua principal estratégia discursiva, é uma forma de conhecimento e identificação que vacila entre o que está sempre "no lugar", já conhecido, e algo que deve ser ansiosamente repetido... como se a duplicidade essencial do asiático ou a bestial liberdade sexual do africano, que não precisam de prova, não pudessem na verdade ser provados jamais no discurso. (BHABHA, 2007, p. 105).

Em contrapartida, nos discursos pós-coloniais - dentre os quais o romance A gloriosa família, de Pepetela, é um exemplo -, o conceito de fixidez é questionado por um olhar que se coloca na periferia do poder e que, ao dialogar com os discursos da colonização, reinscreve a tradição "através das condições de contingência e contrariedade que presidem sobre a vida dos que estão na 'minoria' [...] Ao reencenar o passado, este introduz outras temporalidades culturais incomensuráveis na invenção da tradição" (BHABHA, 2007, p. 21).

Gayatry Spivak, no título de um célebre artigo perguntava: "Can the subaltern speak?". Pepetela, ao colocar como narrador de A gloriosa família um escravo mudo e analfabeto, parece responder afirmativamente a essa questão quando demonstra que um indivíduo do qual não se esperava nada, surpreende e deixa registrado seu testemunho. Como a narrativa evidencia, a impossibilidade de comunicar algo não era sentida por esse "subalterno", pelo contrário, era uma conviç̧ão de seu dono. Baltazar Van Dum, certa vez, ao ser advertido por Domingos Fernandes do perigo que seria comentar determinados assuntos na presença do escravo mulato (já que ele poderia acabar revelando algum segredo), gargalhou e disse:

Não tem perigo. É mudo de nascença. E analfabeto. Até duvido que perceba uma só palavra que não seja em kimbundu... Uma frase se tanto! Como pode revelar segredos? Este é que é mesmo um túmulo, o mais fiel dos confidentes. Confesse-lhe todos os seus pecados, ninguém saberá, nem Deus. (PEPETELA, 1999, p. 393).

Perplexo em ouvir a resposta do dono, o escravo-narrador então afirma: 
Sempre achei que o meu dono subestimava as minhas capacidades. Bem gostaria nesse momento de poder falar para lhe dizer que até francês aprendi nos tempos dos jogos de cartas. E que bem podiam baixar a voz ao mínimo entendível que eu ouvia sem esforço, bastando ajustar o tamanho das orelhas. Mas se tão pouco valor me atribuía, então também não merecia o meu esforço de lhe fazer compreender o contrário, morresse com a sua idéia. Uma desforra para tanto desprezo seria contar toda a sua história, um dia. Soube então que o faria, apesar de mudo e analfabeto. Usando poderes desconhecidos, dos quais se ocultam no pó branco da pemba ou nos riscos traçados nos ares das encruzilhadas pelos espíritos inquietos. Fosse de que maneira fosse, tive a certeza de o meu relato chegar a alguém, colocado em impreciso ponto do tempo e do espaço, o qual seria capaz de gravar tudo tal como testemunhei. (PEPETELA, 1999, p. 393-4).

Em ensaio intitulado "Colonização e globalização, continuidades e contiguidades colocadas no presente de Angola", Ruy Duarte de Carvalho esclarece que Angola é hoje um país marcado por "diferentes temporalidades, e às vezes discordantes, dentro de um mesmo território, quer dizer, lógicas de equilíbrio econômico [...] que se articulam às lógicas do crescimento obrigatório que caracterizam as dinâmicas do sistema global e local de mercado" (2008, p. 36). E, diante do exposto, chama a atenção para a importância de se reconhecer a "indetenibilidade da dinâmica da hegemonia ocidental" (2008, p. 43), mas ao mesmo tempo de se valorizar a contribuição de culturas não-ocidentais e nãoocidentalizadas (como a dos pastores Kuvale), o que implica "convocar o saber e a prática de sistemas endógenos, mesmo no que diz respeito a muitos daqueles que são tidos pelos mais 'arcaicos' ou 'atrasados'” (2008, p. 46).

Desse modo, o que tanto a narrativa de Pepetela como a fala de Ruy Duarte de Carvalho parecem evidenciar é que, seja no século XVII (na época das disputas entre holandeses e portugueses pelo controle do tráfico de escravos), seja na atualidade, existiram e existem pessoas que, consideradas incapazes de dizer algo, foram (e ainda são) silenciadas pela história. A questão que se coloca a partir de então parece ser não mais se o subalterno pode ou não falar, mas sim se há alguém disposto a ouvi-lo.

\section{Referências}

BHABHA, Homi K. O local da cultura. Belo Horizonte: Editora da UFMG, 2007.

CARVALHO, Ruy Duarte de. "Colonização e globalização, continuidades e contiguidades colocadas no presente de Angola" in A câmara, a escrita e a coisa dita... fitas, textos e palestras. Lisboa: Cotovia, 2008.

FOUCAULT, Michel. "A vida dos homens infames" in $O$ que é um autor?. Lisboa: Vega, 2002.

GOULART, Audemaro Taranto. "A gloriosa identidade: a afirmação da literatura africana num romance de Pepetela" in A kinda e a misanga. São Paulo; Luanda: 
Cultura Acadêmica; Nzila, 2007.

HALL, Stuart. "Quando foi o pós colonial? Pensando no limite" in Da diáspora: identidades e mediações culturais. Belo Horizonte: Editora UFMG, 2003.

LEITE, Ana Mafalda. "Pós-colonialismo: um caminho crítico e teórico" in Literaturas Africanas e formulações pós-coloniais. Lisboa: Edições Colibri, 2003.

PEPETELA. A Gloriosa Família: o tempo dos flamengos. Rio de Janeiro: Nova Fronteira, 1999.

SPIVAK, Gayatri Chakravorty. "Can the subaltern speak?" in Marxism and the Interpretation of Culture. Urbana; Chicago: University of Mlinois Press, 1988. 